\title{
Anaesthetic considerations for patients undergoing pre-surgical embolization of intracranial and spinal tumours: An overview
}

\author{
Suparna Bharadwaj, Rebecca Moga, Pirjo Manninen, Lakshmikumar Venkatraghavan
}

\begin{abstract}
Pre-surgical embolization of vascular brain and spinal tumours is an effective method of reducing intraoperative bleeding. Many technological developments of the microcatheters and embolic materials that are used have led to better outcomes in tumour embolization. Pre-operative embolization has become a standard of practice in the management of many vascular brain and spinal tumours. Anaesthesiologists are generally involved with these procedures which may be performed with general anaesthesia, conscious sedation or monitored anaesthesia care. The choice of the anaesthetic technique usually depends on the patient characteristics, tumour location, vascularity of the tumour and most importantly the neuroradiologist and/or institutional preferences. There is limited information in the literature on the anaesthetic considerations for these patients. The aim of this review is to provide a brief overview of the indications, techniques, complications and relevant anaesthetic considerations for patients undergoing pre-surgical embolization of intracranial and spinal tumours.
\end{abstract}

Key words: Anaesthesia, brain and spinal tumours, complications, presurgical embolization

\section{INTRODUCTION}

Pre-surgical embolization of vascular brain and spinal tumours is an effective method of reducing intraoperative bleeding. ${ }^{[1]}$ Many technological developments of the microcatheters and embolic materials that are used have led to better outcomes in tumour embolization. ${ }^{[2]}$ Pre-operative embolization has become a standard of practice in the management of many vascular brain and spinal tumours. ${ }^{[2-5]}$ Anaesthesiologists are generally involved with these procedures which may be performed with general anaesthesia, conscious sedation or monitored anaesthesia care. The choice of the anaesthetic technique usually depends on the patient characteristics,

\begin{tabular}{|l|l|}
\hline \multicolumn{2}{|c|}{ Access this article online } \\
\hline Quick Response Code: & Website: \\
\hline & www.jnaccjournal.org \\
\cline { 2 - 2 } & \\
\hline
\end{tabular}

tumour location, vascularity of the tumour and most importantly the neuroradiologist and/or institutional preferences. There is limited information in the literature on the anaesthetic considerations for these patients. The aim of this review is to provide a brief overview of the indications, techniques, complications and relevant anaesthetic considerations for patients undergoing pre-surgical embolization of intracranial and spinal tumours.

\section{INTRACRANIAL TUMOURS}

\section{Indications and benefits of pre-surgical embolization}

The ideal treatment for intracranial tumours is complete or radical surgical resection, thus decreasing the incidence of tumour recurrence. ${ }^{[6]}$ Factors that affect the ability to completely resect the tumour include the proximity of eloquent brain to the tumour, vascularity of the tumour, encasement of the tumour around major arteries or cranial nerves and the involvement of a dural venous sinus. Embolization involves the

Department of Anesthesiology, Toronto Western Hospital, Toronto, Ontario, Canada

Address for correspondence:

Dr. Lakshmikumar Venkatraghavan, Department of Anesthesiology, Toronto Western Hospital, 399, Bathurst Street, Toronto, Ontario, Canada.

E-mail: Lashmi.Venkatraghavan@uhn.on.ca 
devascularization of the blood supply to the tumour by placement of an embolic agent via a microcatheter into the feeding arteries. Devascularization by pre-surgical embolization can help in the complete resection of the tumour by decreasing the intraoperative blood loss and thus the operative time. Tumours that are commonly treated with pre-surgical embolization are shown in Table 1. ${ }^{[6]}$

\section{Embolization techniques}

Vascular supply of the tumour varies with location, size and the type of the tumour. Typically, hypervascular brain tumours can be supplied from both the external carotid (ECA) and the internal carotid arteries (ICA). The first step in embolization is to do a diagnostic ECA, ICA and vertebral artery angiograms to identify blood supply of the tumour and to assess the safety and feasibility of embolization. Then selective catheterizations of the feeding arteries are done to further analyze the arterial supply of the tumour. A microcatheter is navigated through the larger diagnostic angiography catheter and is directed over a micro-guidewire to the artery supplying the tumour. ${ }^{[7]}$ The general goal is to embolize the surgically inaccessible arterial feeders. Tumours with blood supply from both the ECA and ICA often exhibit increased flow from the ICA after occlusion of the ECA feeders. ${ }^{[8]}$ In addition, super-selective catheterization of ECA branches may also reveal some important intracranial anastomoses with pial vessels supplying eloquent brain, which should be preserved during embolization. In these cases, embolization of the ECA feeders may be of limited benefit, and may even be contraindicated. Similarly in tumours that cross the midline, evaluation of the contralateral carotid branches should be done to exclude their contribution to tumour vascularity. ${ }^{[9]}$ The feeding arterial supply to cranial nerves should be ruled out before infusion of embolic agents. ${ }^{[10]}$ Occasionally, a non-detachable balloon is inflated above the origin of the feeding arteries to protect the ophthalmic artery and pial arterial branches from embolic agent migration. ${ }^{[11]}$

\section{Embolic material and related complications}

The choice of embolic material usually depends on the operator's preference and experience. Embolic materials have their ownadvantages and limitations. ${ }^{[12,13]}$ Commonly

\section{Table 1: Indications of presurgical embolisation of intracranial tumours}

\begin{tabular}{ll}
\hline Extra axial & Intra-axial \\
\hline Meningioma & Haemangioblastoma \\
Paraganglioma & Metastasis \\
$\begin{array}{l}\text { Haemangiopericytoma } \\
\text { Juvenile nasopharyngeal } \\
\text { angiofibroma }\end{array}$ & Ependymoma \\
\hline
\end{tabular}

used embolic materials include both particulate and liquid agents such as N-butyl cyanoacrylate (glue) and ethylene vinyl alcohol copolymer (Onyx). In the case of particulate materials such as polyvinyl alcohol or trisacryl gelatin microspheres (TAGM), the size of the particles have been linked to both efficacy and complication rates. ${ }^{[14]}$ While smaller particles are able to penetrate more into tumour capillary beds, they can also cause injury to the vasa nervorum resulting in cranial nerve palsies. Further, the embolic material can enter the intracranial circulation through anastomoses of the ECA and ICA. ${ }^{[15]}$ The glue entering the circulation can cause vessel occlusion secondary to a strong inflammatory reaction in the vessel wall leading to endothelial injury and necrosis. The arterial occlusion caused by glue lasts for about 30 days. ${ }^{[16,17]}$ There are complications associated with these procedures. ${ }^{[18]}$ Transarterial embolization with onyx may not result in tumour penetration, particularly when it is injected from a long distance through small caliber or slow flow vessels. Another option for embolization is the pre-operative intraparenchymal injection of onyx mostly for juvenile nasopharyngeal angiofibraoma. A direct transnasal puncture of the tumour is performed with endoscopic guidance and onyx is injected. ${ }^{[19]}$ A prior knowledge of intra tumoural vascular anatomy is essential to rule out dangerous extracranial to intracranial anastomoses.

\section{Anaesthetic considerations}

Hypervascular intracranial tumours usually have intra-tumour anastomotic channels and vasogenic cerebral oedema surrounding the tumour due to increased vascularity. Thus, cerebral autoregulation may be compromised around the tumour. Impaired autoregulation is an important consideration in the anaesthetic management of these patients. The anaesthetic approach depends on the patient profile and neuroradiologist and/or institutional preferences. In co-operative adults the anaesthetic management may be with conscious sedation or monitored anaesthesia care and local anaesthesia for the femoral artery puncture. ${ }^{[20]}$ General anaesthesia is required for those patients who cannot tolerate being awake or sedated, or lying still for prolonged periods. This includes patients who are unco-operative as any slight movement by the patient may cause image distortion. As well there is a need for frequent episodes of apnoea for good image quality. Controlled ventilation may be required if the patient has increased intracranial pressure (ICP).

\section{Preoperative evaluation and pre-medication}

In addition to routine pre-anaesthetic evaluation, particular attention should be paid to evaluate the neurological status of the patient such as level of consciousness, history of increased ICP and neurological deficits. Other assessments include medical 
comorbidities, allergic reactions to radiologic contrast dyes and protamine, history of prior anticoagulation or coagulation disorders and any recent steroid use. ${ }^{[21]}$ For patients with allergy to radiological contrast dyes, oral or intravenous (IV) pre-medication regimen with steroids and supplemental H1 antihistaminic agents may be considered. ${ }^{[22]}$ In patients with history of a previous anaphylactic reaction to iodinated contrast medium, pre-operative, intratumoural injection of onyx is an option. If a procedure is contemplated under conscious sedation, the patient's tolerance to lying supine for several hours should also be assessed. All routine medications should be continued including dexamethasone and antiepileptic drugs.

\section{Anaesthetic technique}

Ideally, an interventional radiology suite should be equipped for anaesthetic care similar to a standard operating room. All standard routine monitors are used in all patients whatever the anaesthetic technique is (electrocardiogram, non-invasive blood pressure, pulse oximeter, end tidal carbon dioxide monitoring). Additional monitoring used during general anaesthesia may include temperature, neuromuscular and end tidal gas monitoring. Invasive monitoring (intra-arterial catheter) may be used as indicated by the patient or procedure. An urinary catheter is usually inserted, as there will be an osmotic load from the contrast medium and additional fluid load from intra-arterial saline flushing of the microcatheters by the radiologist. Patients with rare catecholamine-secreting paragangliomas may benefit from invasive monitoring during the procedure to control blood pressure fluctuations. The choice of agents for sedation or for general anaesthesia should reflect the need for haemodynamic stability, and the medical and neurological requirements of the patients. Conscious sedation may be performed with a number of different agents including midazolam, propofol, dexmedetomedine and opioids such as fentanyl or remifentanil. These may be administered as infusions, boluses or as target controlled infusions. The level of sedation will vary but often usually reflects a sedation score of 3 in the Modified sedation scoring ${ }^{[23]}$ where the patient is drowsy but arousable for provocative tests and neurological assessments.

The agents used for induction and maintenance of general anaesthesia should reflect the goals of anaesthesia for any patient with an intracranial lesion. This includes the possibility of impaired autoregulation in and around hypervascular tumours, haemodynamic stability and possible increased ICP. There is no definite consensus as to the best technique between balanced anaesthesia with inhalation agents and total IV anaesthesia (TIVA). ${ }^{[6]}$ Endotracheal intubation is generally used but laryngeal mask may be acceptable in some situations. Ventilation is controlled to achieve normocapnoea and prevent hypercapnia. Haemodynamics are maintained at pre-procedure parameters. Bispectral index (BIS) monitoring serves dual purposes. In addition to monitoring depth of anaesthesia, BIS may be of help to diagnose periprocedural cerebral insults. ${ }^{[24-26]}$ Emergence from anaesthesia in neurosurgical patients is aimed to be early and smooth along with stable haemodynamics. ${ }^{[27]}$ An additional responsibility of the anaesthesiologist is the administration of heparin. Patients are anticoagulated to prevent thrombosis with the insertion of the microcatheters and during the embolization. After a baseline activated clotting time (ACT) is obtained, intravenous heparin (70 units $/ \mathrm{kg})^{[20]}$ is generally given to a target prolongation of approximately 2 to 3 times the baseline value. Then heparin can be given continuously or as an hourly intermittent boluses with monitoring of ACT. Heparin may be reversed with protamineat the end of the procedure with the removal of the femoral catheter. Protamine ${ }^{[20]}$ at $1 \mathrm{mg}$ for each 100 units of total heparin dose will result in therapeutic anticoagulation. The ACT can then be used to fine-tune the final protamine dose. The use of VasoSeal (a collagen plug) is a safe and effective method of achieving haemostasis after femoral artery catheter removal that eliminates the need for protamine and can hasten time to hemostasis, ambulation and discharge. ${ }^{[28]}$

\section{Intra-procedure neurological monitoring}

Local anaesthesia and conscious sedation allows for neurologic examination of an awake patient during provocative testing maneuvers. Provocative testing includes injection of a small dose of amytal or lidocaine to identify vasa nervorum (blood supply to cranial nerves) beyond the microcatheter tip. The development of a temporary cranial nerve deficit after such a provocative test increases the risk of embolization and may warrant catheter repositioning. After the microcatheter has been properly and safely positioned, embolic material is injected under constant, real-time digital-subtraction fluoroscopy, to allow penetration of the material into the tumour bed. ${ }^{[29,30]}$ Balloon occlusion testing is obligatory in cases where internal carotid artery sacrifice is necessary. ${ }^{[31]}$ These procedures are usually performed with an awake patient. Whether outcomes are improved using the above testing is not known, so the decision to use adjunct testing or monitoring should be individualized. Evoked potentials (somatosensory and motor evoked potentials) may be used during embolization as well as during provocative tests with amobarbital when general anaesthesia is used. ${ }^{[13]}$ When properly evaluated before treatment, tumours of the eloquent cortex can be embolized with a high success rate and a low complication rate. 
Management of neurological catastrophes during intracranial tumour embolization

The major neurological complications include cranial nerve palsy, ischemic or haemorrhagic stroke and death. In a recent study, Bendszus et al. reported a complication rate of $6.4 \%$ in a series of 185 patients. The incidence of haemorrhagic and ischemic complications were the same. ${ }^{[32,33]}$ The catastrophes during embolization of a tumour can be rapid and dramatic, and urgent treatment may be required. There must be effective communication between the neuroradiologist and anaesthesiologist to determine the extent and nature of the problem. The primary responsibility of the anaesthesia team will be to secure the airway and preserve gas exchange, if conscious sedation is used. In case of an occlusive problem, blood pressure should be augmented to increase distal perfusion with or without direct thrombolysis. If the problem is haemorrhagic, heparin is reversed with protamine ${ }^{[20]}$ The radiologist can attempt to seal the rupture site endovascularly and abort the embolization procedure. A ventriculostomy catheter may be placed emergently in the angiography suite to drain cerebrospinal fluid to treat intracranial hypertension. ${ }^{[20]}$ Further management is based on the patient's clinical and radiological findings. Patient may be transferred for diagnostic computerized tomography/magnetic resonance imaging and then either to an intensive care unit or to the operating room for haematoma evacuation. Whether the patient is woken up from anaesthesia at this stage will depend on the severity of the event. However, patient will continue to need close haemodynamic and neurological monitoring. Dexamethasone should be considered for evidence of increase in peritumoural oedema during embolization.

\section{Post-procedure management}

All patients following embolization should be shifted to a post-anaesthetic care unit (PACU) or in a neuro intensive care unit for haemodynamic and neurological monitoring. As well all standard PACU care is given which includes treatment for nausea and vomiting and pain. Deliberate hypotension or hypertension is employed as per the merit of the case in the post-embolization period.

\section{Embolization of spinal tumours}

Overall the management of patients for embolization of spinal tumours is similar to that of patients with intracranial tumours. Spinal tumours that may be embolized are shown in Table 2.

The most frequently used embolic agent for spinal tumour embolization is polyvinyl alcohol (PVA) particles which are non-biodegradable. ${ }^{[34]}$ These PVA particles of 150-250 $\mu \mathrm{m}$ diameter allow relatively distal embolization with occlusion at the capillary level, because the capillaries within the tumour are usually about $200 \mu \mathrm{m}$ in diameter. Single-plane digital subtraction angiography
Table 2: Indications of presurgical embolisation of spinal tumours

\begin{tabular}{ll}
\hline Intradural & $\begin{array}{l}\text { Extradural vertebral body } \\
\text { tumours/metastasis }\end{array}$ \\
\hline Meningioma & Giant cell tumours \\
Schwannoma & Multiple myeloma \\
Meningiopericytoma & Metastasis from renal cell carcinoma \\
Haemangioblastoma & $\begin{array}{l}\text { Metastasis from hepato cellular } \\
\text { carcinoma }\end{array}$ \\
& $\begin{array}{l}\text { Paraganglioma } \\
\text { Aneurysmal bone cyst } \\
\end{array}$ \\
& Haemangioma \\
\hline
\end{tabular}

may be carried out to identify the blood supply to the spinal tumour and the location of the anterior and posterolateral spinal arteries. Particle embolization is carried out from the segmental artery with the tip of the microcatheter positioned just proximal to the origin of the spinal branch. Before this, the segmental artery distal to the spinal branch may be occluded (distal takedown) by the placement of non-detachable coils to induce flow diversion into the spinal mass and avoid unnecessary distal bed embolization. ${ }^{[35]}$ Once stasis is achieved after flow-directed polyvinyl alcohol particle infusion, liquid or fibered platinum coils can be deployed to occlude the segmental artery proximally. This eliminates the antegrade pressure head in the feeding pedicle and further decreases the likelihood of recanalization before surgery. ${ }^{[35]}$ The presence of an anterior spinal artery from a tumour feeder is an obvious contraindication for embolization. ${ }^{[36]}$ The untoward embolization of an anterior spinal artery may injure the pyramidal tracts and cause a severe motor deficit. ${ }^{[37]}$

There is limited information regarding the preferred anaesthesia techniques for spinal tumour embolization. Generally, the anaesthetic considerations are similar to those for intracranial tumour embolization. Though awake patients are preferred for periodic neurological assessment during the procedure, need of frequent apnoea intervals and the stillness of the patient are limiting factors. Pharmacological provocative tests (with amytal or lidocaine) using evoked potentials under general anaesthesia may avoid complications. ${ }^{[38]}$ Provocative tests are performed with intra-arterial injection of short acting barbiturates (Amytal) or Lidocaine (Xylocaine) through the microcatheter. A positive provocative test (i.e., more than $50 \%$ decrease in somatosensory evoked potential (SSEP) amplitude and/or motor evoked potential (MEP) disappearance) indicates that the vessel distal to the tip of the micro catheter supplies functional gray or white matter of the spinal cord respectively. Embolization from the same catheter position where provocative tests is positive is not performed. 


\section{CONCLUSION}

Pre-operative embolization of highly vascular intracranial and spinal tumours is frequently performed. Anaesthesiologists are involved in the complex care of these patients during intra- and post-procedure management as well as the surgical excision of the tumour. Embolization can be performed safely using either local anaesthesia with conscious sedation or general anaesthesia. ${ }^{[39]}$ To date, no studies have compared complication rates with the different techniques during intracranial and spinal tumour embolization. The choice of anaesthesia should therefore be guided by patient specific characteristics and the neuroradiologist preferences. Future well-designed prospective clinical studies are needed to investigate the influence of such factors on patient outcome and provide critical evidence to guide clinical practice.

\section{REFERENCES}

1. Hekster RE, Matricali B, Luyendijk W. Presurgical transfemoral catheter embolization to reduce operative blood loss. Technical note. J Neurosurg 1974;41:396-8.

2. Ahuja A, Gibbons KJ, Hopkins LN. Endovascular techniques to treat brain tumours. In: Youmans JR editor. Neurological Surgery. $4^{\text {th }}$ ed., vol. 4. Philadelphia: WB Saunders; 1996. p. 2826-40.

3. Sakamoto N, Ishikawa E, Nakai Y, Akutsu H, Yamamoto T, Nakai K, et al. Preoperative endovascular embolization for hemangioblastoma in the posterior fossa. Neurol Med Chir (Tokyo) 2012;52:878-84.

4. Wang HH, Luo CB, Guo WY, Wu HM, Lirng JF, Wong TT, et al. Preoperative embolization of hypervascular pediatric brain tumours: Evaluation of technical safety and outcome. Childs Nerv Syst 2013;29:2043-9.

5. Manke C, Bretschneider T, Lenhart M, Strotzer M, Neumann C, Gmeinwieser J, et al. Spinal metastases from renal cell carcinoma: Effect of preoperative particle embolization on intraoperative blood loss. AJNR Am J Neuroradiol 2001;22:997-1003.

6. Duffis EJ, Gandhi CD, Prestigiacomo CJ, Abruzzo T, Albuquerque F, Bulsara KR, et al.; Society for Neurointerventional Surgery. Head, neck and brain tumour embolization guidelines. J Neurointerv Surg 2012;4:251-5.

7. Lasjaunias P, Berenstein. A Surgical Neuroangiography. Endovascular Treatment of Craniofacial Lesions. Vol. 2. Berlin: Springer-Verlag; 1987.

8. Manelfe C, Lasjaunias $\mathrm{P}$, Ruscalleda J. Preoperative embolization of intracranial meningiomas. AJNR Am J Neuroradiol 1986;7:963-72.

9. Valavanis A, Christoforidis G. Applications of interventional neuroradiology in the head and neck. Semin Roentgenol 2000;35:72-83.

10. Geibprasert S, Pongpech S, Armstrong D, Krings T. Dangerous extracranial-intracranial anastomoses and supply to the cranial nerves: Vessels the neurointerventionalist needs to know. AJNR Am J Neuroradiol 2009;30:1459-68.

11. Tymianski M, Willinsky RA, Tator CH, Mikulis D, TerBrugge KG, Markson L. Embolization with temporary balloon occlusion of the internal carotid artery and in vivo proton spectroscopy improves radical removal of petrous-tentorial meningioma. Neurosurgery 1994;35:974-7.

12. Sekhar LN, Biswas A, Hallam D, Kim LJ, Douglas J, Ghodke B.
Neuroendovascular management of tumours and vascular malformations of the head and neck. Neurosurg Clin N Am 2009;20:453-85.

13. Carli DF, Sluzewski M, Beute GN, van Rooij WJ. Complications of particle embolization of meningiomas: Frequency, risk factors, and outcome. AJNR Am J Neuroradiol 2010;31:152-4.

14. Wakhloo AK, Juengling FD, Van Velthoven V, Schumacher M, Hennig J, Schwechheimer K. Extended preoperative polyvinyl alcohol microembolization of intracranial meningiomas: Assessment of two embolization techniques. AJNR Am J Neuroradiol 1993;14:571-82.

15. Bendszus M, Klein R, Burger R, Warmuth-Metz M, Hofmann E, Solymosi L. Efficacy of trisacryl gelatin microspheres versus polyvinyl alcohol particles in the preoperative embolization of meningiomas. AJNR Am J Neuroradiol 2000;21:255-61.

16. Leonardi M, Barbara C, Simonetti L, Giardino R, Aldini NN, Fini M, et al. Glubran 2: A new acrylic glue for neuroradiological endovascular use. Experimental study on animals. Interv Neuroradiol 2002;8:245-50.

17. Leonardi M, Cenni P, Simonetti L, Bozzao A, Romano A, Bonamini $\mathrm{M}$, et al. Glubran 2((r)): New acrylic glue for neuroradiological endovascular use: A complementary histological study. Interv Neuroradiol 2003;9:249-54.

18. Raffi L, Simonetti L, Cenni P. Use of Glubran 2 acrylic glue in interventional neuroradiology. Neuroradiology 2007;49:829-36.

19. Elhammady MS, Wolfe SQ, Ashour R, Farhat H, Moftakhar R, Lieber BB, et al. Safety and efficacy of vascular tumour embolization using Onyx: Is angiographic devascularization sufficient? J Neurosurg 2010;112:1039-45.

20. Lee CZ, Young WL. Anesthesia for endovascular neurosurgery and interventional neuroradiology. Anesthesiol Clin 2012;30:127-47.

21. Sinha PK, Neema PK, Rathod RC. Anesthesia and intracranial arteriovenous malformation. Neurol India 2004;52:163-70.

22. ACR Committee on Drugs and Contrast Media. ACR Manual on Contrast Media - Version 9, 2013

23. Ramsay MA, Savage TM, Simpson BR, Goodwin R. Controlled sedation with alphaxalone-alphadolone. Br Med J 1974;2:656-9.

24. Unnikrishnan KP, Sinha PK, Sriganesh K, Suneel PR. Case report: Alterations in bispectral index following absolute alcohol embolization in a patient with intracranial arteriovenous malformation. Can J Anaesth 2007;54:908-11.

25. Welsbey IJ, Ryan JM, Booth JV, Flanagan E, Messier RH, Borel CO. The bispectral index in the diagnosis of perioperative stroke: A case report and discussion. Anesth Analg 2003;96:435-7.

26. Hayashida M, Chinzei M, Komatsu K, Yamamoto H, Tamai H, Orii $\mathrm{R}$, et al. Detection of cerebral hypoperfusion with bispectral index during paediatric cardiac surgery. $\mathrm{Br} \mathrm{J}$ Anaesth 2003;90:694-8.

27. Jaeger $K$, Ruschulte $H$, Herzog $T$, Heine J, Leuwer $M$, Piepenbrock S. Anaesthesiological and criterial care aspects regarding the treatment of patients with arteriovenous malformations in interventional neuroradiology. Minim Invasive Neurosurg 2000;43:102-5.

28. Schickel SI, Adkisson P, Miracle V, Cronin SN. Achieving femoral artery hemostasis after cardiac catheterization: A comparison of methods. Am J Crit Care 1999;8:406-9.

29. Dowd CF, Halbach VV, Higashida RT Meningiomas: The role of preoperative angiography and embolization. Neurosurg Focus 2003;15:E10.

30. Kai Y, Hamada J, Morioka M, Yano S, Nakamura H, Makino K, et al. Preoperative cellulose porous beads for therapeutic embolization of meningioma: Provocation test and technical considerations. Neuroradiology 2007;49:437-43. 
31. Accreditation council on graduate medical education. Carotid artery balloon test occlusion. supplement to AJNR Am J Neuroradiol 2001;22:s9.

32. Paulsen RD, Steinberg GK, Norbash AM, Marcellus ML, Lopez JR, Marks MP. Embolization of rolandic cortex arteriovenous malformations. Neurosurgery 1999;44:479-84.

33. Bendszus M, Monoranu CM, Schütz A, Nölte I, Vince GH, Solymosi L. Neurologic complications after particle embolization of intracranial meningiomas. AJNR Am J Neuroradiol 2005;26:1413-9.

34. Gruber A, Bavinzski G, Killer M, Richling B. Preoperative embolization of hypervascular skull base tumours. Minim Invasive Neurosurg 2000;43:62-71.

35. Thiex R, Gross BA, Gupta R, Wyers MC, Frerichs KU, Thomas AJ. Transvenous approach to carotid-cavernous fistula via facial vein cut down. J Clin Neurosci 2014;21:1238-40.

36. Latchaw RE, Gold LH. Polyvinyl foam embolization of vascular and neoplastic lesions of the head, neck, and spine. Radiology
1979;131:669-79.

37. Smith TP, Gray L, Weinstein JN, Richardson WJ, Payne CS. Preoperative transarterial embolization of spinal column neoplasms. J Vasc Interv Radiol 1995;6:863-9.

38. Sala F, Nimmi Y, Bernstein A, Deletis V. Role of multimodality intraoperative neurophysiological monitoring during embolisation of a spinal cord arteriovenous malformation. Interv Neuroradiol 2000;6:223-4.

39. Shi HB, Suh DC, Lee HK, Lim SM, Kim DH, Choi CG, et al. Preoperative transarterial embolization of spinal tumour: Embolization techniques and results. AJNR Am J Neuroradiol 1999;20:2009-15.

How to cite this article: Bharadwaj S, Moga R, Manninen P, Venkatraghavan L. Anaesthetic considerations for patients undergoing pre-surgical embolization of intracranial and spinal tumours: An overview. J Neuroanaesthesiol Crit Care 2015;2:104-9.

Source of Support: Nil, Conflict of Interest: None declared. 